\title{
Advances in rehabilitation:
}

\section{an overview and an odyssey}

\author{
M Anne Chamberlain
}

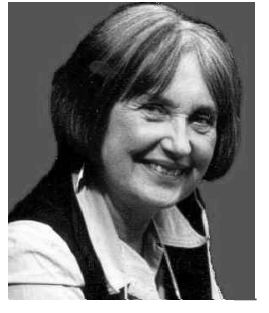

This article is

based on the

Bradshaw Lecture given at the Royal

College of

Physicians on 25

April 2001 by

M Anne

Chamberlain $\mathrm{OBE}$ FRCP FRCP CH,

Charterhouse

Professor of

Rehabilitation

Medicine,

University of Leeds;

Chairman, Joint Specialty

Committee for

Rehabilitation

Medicine, RCP

Clin Med

2003;3:62-7
KEY WORDS: ageing, chronic disability,
rehabilitation, service provision, work incapacity

\section{Introduction}

Homer's The Odyssey ${ }^{1}$ is a tale of adventure, and endurance. Its goal was very clear, driving Odysseus and his men to solve a multiplicity of problems. My contention is that the full flowering of rehabilitation practice and research are similarly important aims driving on their proponents, to the considerable benefit of the health service. The goal is the proper practice of rehabilitation accessible to all who need it, with practice based on sound research.

The modern NHS will be less and less about the cure of isolated disease episodes, and more and more about the amelioration of chronic disease. To plan services effectively, it is therefore useful to:

- have some knowledge of the population who will need rehabilitation services in 2010

- briefly survey advances and difficulties of the last decade

- appraise current research needs and opportunities

- identify barriers to the translation of research into practice.

This is therefore the content of this paper.

\section{The population who will need rehabilitation in 2010}

The life expectancy of a baby born now in the UK is 75 years for a boy, and 80 years for a girl. This includes some five years lived with disability, ie $7 \%$ of the total lifespan. ${ }^{4}$

In many parts of the world the situation is dramatically different. For instance in Zimbabwe, life expectation is 40 years and falling. The expectation of years of disability is much the same (seven years) but the proportion of life with disability approaches $19 \%$. In places like India, the burden of AIDS may be lower, but that of ageing is not. In both richer and poorer worlds, demographic factors point to the need for rehabilitation and alleviation of disability. However, many of these countries have more immediate problems, so rehabilitation is poorly developed and services across populations are rarely coordinated.

The above hotly debated WHO figures tell us little about the nature of disability or service response, although we know something of both of these in the UK. However, they suggest that there is merit in doing what Callahan sees as important: 'Give the "compression of morbidity" a research status equivalent to that now given to the prolongation of life'. $^{5}$

\section{UK epidemiology of disability}

From the Office of Population, Censuses and Surveys figures, now almost 20 years old, we know that disability affects one in eight of our population and its prevalence climbs steeply over the age of 50 years to reach very high levels in the very elderly. ${ }^{6}$

There are several important, mostly younger, groups which we should be aware of. An important cohort, now of pensionable age, is that with the 'postpolio syndrome.' This needs to be more widely recognised, being partially amenable to interventions. ${ }^{7}$ There are several other groups in those of working age, which are discussed below.

\section{Disability in those of working age}

The major causes of adult disability are two fluctuant and progressive conditions: inflammatory arthritis and multiple sclerosis. In addition, there are a significant number of people who have a variety of rare, mainly degenerative, neurological conditions requiring similar interventions. Some of these present in childhood. One such is spina bifida. In 1988, when we founded a specialist community rehabilitation team for young physically disabled adults negotiating transition from childhood to adulthood, these people were major clients. Now we hear little of them in health service terms though we may expect premature ageing. Another cohort, some 10 years older, is of those with thalidomide-induced impairments. There are only about 400 people affected in the UK but already they are experiencing musculoskeletal limitations and pain.

But the largest group is of those with cerebral palsy. Hutton, in the north east of England, studied 
those born in 1960-90. ${ }^{8}$ The majority attained adulthood, though more than one-third of those with severe disability (mainly cognitive and motor) died before the age of 30 . Stevenson highlighted their need for transition services. ${ }^{9}$ Although there are improvements in transition arrangements in education and social services, few health-based services are available to deal with these people's rehabilitation needs as they attempt to become mature adults, to work, to be relatively independent and use health services effectively. They do not require a disease-specific service; they need access to a generic, community-based rehabilitation team. Paediatricians, who are exercised by their disabled children leaving their service, ${ }^{10}$ need to be made aware of what these teams can do.

Very small babies (born around 20-24 weeks) are now surviving, sometimes at heavy cost and with major disability. Doyle showed that of children with a birth weight below $1000 \mathrm{~g}$, at 14 years, of the $25 \%$ who survived, $29 \%$ were moderately or severely disabled compared with the $2 \%$ of those of normal birth weight. $^{11}$

Trauma costs the UK a great deal of money. The Royal College of Surgeons of England and the British Orthopaedic Association, in their report, Better care for the severely injured, ${ }^{12}$ put the cost of severe injury at $\mathfrak{E} 1.2$ billion to the health and social services. It was stated in a newspaper article ${ }^{13}$ related to this report that 10,000 children are left permanently disabled after accidents but hard information is sparse, especially about the nature of sequelae or whether these children receive adequate rehabilitation. A recent paper by Sturms in Holland concludes that traffic accidents are a major cause of severe residual disability and states 'outcome of non-fatal injuries in terms of disabilities needs more attention. ${ }^{14}$

One of the traditional responses to disability in adults of working age in the UK used to be a countrywide network of medical rehabilitation centres ${ }^{15}$ where those with disability could be assessed, and receive therapy. Assessment, including vocational rehabilitation, took place over weeks, as physical and skill abilities changed. This service could be followed by employment rehabilitation where clinical input continued to be available. In the most innovative development, at Garston Manor, medical rehabilitation took place alongside employment rehabilitation with great benefit to the individual and increased understanding in staff of both medical and employment services.

Today all 25 specialist centres described by Mattingley have gone; ${ }^{15}$ resettlement officers no longer exist; information on patients' work assessments done by a disability services team cannot be passed to a rehabilitation physician or therapist as of right, and we have a large number of people going on to Incapacity Benefit and few coming off (for every 200 going on, only ten come off). The recent British Society of Rehabilitation Medicine (BSRM) document, ${ }^{16}$ the Trade Union Congress ${ }^{17}$ and the Association of British Insurers all highlight the same inadequate health services response. There is probably a short window of opportunity after the beginning of sickness absence, up to six months (at which time Incapacity Benefit can be awarded), when vocational rehabilitation is maximally effective.
Yet a survey quoted in the BSRM document stated that organisations of and for disabled people saw the NHS as unable to respond to this need for urgent work-focused intervention. They cited long waiting times to see consultants, to obtain investigations and to begin rehabilitation; overall an approach that was often inadequate and inflexible.

The situation appears to be similar for the staff of the NHS. Pattani showed great loss of staff through early retirement, apparently with little attempt at finding more appropriate work. $^{18}$

The population at risk is probably large. Lerner questioned 940 employed people and found that $19.3 \%$ were limited in performing physical work, $24.6 \%$ in responding to psychosocial demands and $13 \%$ had difficulties in the ambient work environment. ${ }^{19}$

Finally, increasingly sophisticated surgical interventions will need to be maximised by rehabilitation. The author knows of no estimates of projected need.

In summary, in the next decade, those who will need rehabilitation services will be not only the elderly but also those of working age who have experienced trauma, work loss, complex health interventions or who have complex disabilities.

How far have we laid the foundations for an adequate response to these needs?

\section{The advances and difficulties of the last two decades}

Advances have been substantial. A stream of legislation has improved the social and political climate for disabled people; and the physical barriers to participation, whilst still major, have been reduced. Several policy documents from medical organisations and from the Royal College of Physicians have helped (see Table 1).

Whilst rehabilitation was practised by doctors in the UK before 1984, the establishment of the British Society of Rehabilitation Medicine (previously the Medical Disability

Table 1. Some important legislation and policy documents which have helped disabled individuals.

- Chronic Sick and Disabled Persons Act 1970

- NHS and Community Care Act 1990

- Children Act 1989

- Disability Discrimination Act 1995

- Physical Disability in 1986 and beyond. A report of the Royal College of Physicians. J Roy Coll Physicians Lond 1986;20(3)

- People in hospital, 1998; Disabled people using hospital: a charter and guidelines. London: Royal College of Physicians, 1998

- Rehabilitation of Disabled People (Council of Europe)

- Rehabilitation. Geneva: WHO, 1981, 1994

- BSRM policy statements (Advice to purchaser, Multiple sclerosis etc)

- Fully equipped. London: Audit Commission, 2000 


\section{Key Points}

\section{Rehabilitation practice has seen many advances in the last 20 years in terms of service provision, technology, understanding of neuroplasticity and measurement}

\section{The principal loss of service is in vocational rehabilitation}

The principal demographic factors for the decade will include ageing, specific cohorts such as those with cerebral palsy and small, disabled babies surviving into adult life, trauma and work incapacity

Rehabilitation is effective but major sustained research programmes are needed to provide the evidence base for continued progress

Society) in 1990 and the recognition of rehabilitation medicine as a separate specialty within the Royal College of Physicians have been of considerable importance. The specialty has grown rapidly and now has some 116 whole-time employed consultants and a well-structured training programme. But given the work to be done (each consultant should serve a population of 180,000) many more trainees are required.

These consultants have put in many new services, many evaluated, for people aged mainly 16-65 years. The model of a network of services which we have developed in Leeds is probably widely applicable to regions with a mainly urbanised population (Fig 1) but lacks fully developed vocational rehabilitation. The development of innovative practice was considerably helped by pump-priming monies from what was then the Nuffield Provincial Hospitals Trust, just as the development of rehabilitation research teams was greatly facilitated by dedicated central NHS research and development funding. Sadly this no longer exists.

The development of rehabilitation services owes much to Warren's pioneering work in geriatrics. ${ }^{20}$ Mulley quotes the dramatic effects she had on the occupancy of innumerable beds by older people with chronic conditions ${ }^{21}$ (the effect was so large that controlled study was quite unnecessary). Sadly, whilst Mulley wrote of the more recent successes of rehabilitation, both Ebrahim $^{22}$ and Young ${ }^{23}$ have expressed anxieties. The odyssey of developing effective rehabilitation services for older and for younger people is not without setbacks.

Whilst the practice of rehabilitation is now acknowledged to be effective in the areas studied, ${ }^{24,25}$ progress is now more likely to come from the assessment of specific interventions than from the evaluation of global packages of rehabilitation. Many interventions need to be rigorously assessed. Progress in research will be slowed by lack of finances and clinically by the shortage of therapists. Odysseus encountered many hazards, many rocky places. These are all too evident in the funding of research which is rarely sustained, as in cancer research, giving experienced teams time to exploit their abilities fully.

The McColl Report of $1986^{26}$ highlighted the deficiencies of the limb-fitting services, and recommended that it be brought into the NHS. This has been done, for the most part well, so that the recent National Audit Commission's report, Fully equipped, found few major faults. ${ }^{27}$ It points instead to other areas needing improvement. Over one million people in the community use equipment, yet investment in these services is low and there are major problems of coordination and organisation. Our English orthotics services were described in the same document as
Fig 1. A model of city-wide rehabilitation services.

IP = inpatient; OP = outpatient; $\mathrm{TBI}=$ traumatic brain injury. Note: no arrows have been used as all services are accessible whatever the route of entry to the network (provided admission criteria are met).

Acute teaching hospital

\section{Rehabilitation liaison services}

IP subacute rehabilitation service (regional with stroke, TBI, and other diagnoses)

OP rehabilitation medicine
$\quad$ clinics
Botulinum clinic
Specialist seating
Prosthetics
Orthotics
Gait analysis
Brain injury

OP single therapy services

Occupational therapy (including vocational rehabilitation)

Physiotherapy

Speech and language therapy

\section{Community rehabilitation}

Liaison health visitor Stroke rehabilitation Domiciliary services

Community aphasia service At university

Voluntary services

Stroke visitors

Stroke club

Multiple sclerosis centre Other

Disabled living centre

Joint loans store

Primary care
Specialist community rehabilitation

Community rehabilitation unit (focused IP goal-orientated bursts of multidisciplinary therapy)

Young adult team For 16- to 25-year-olds

Head injury team

Continence service

Assistive technology service 
'rudderless' and uncoordinated, with long waiting times and little clinical audit. Yet these services are capable of delivering what is greatly needed: high quality provision at low cost. It is probably not unrelated that little research funding or expertise exists in this area.

One of the problems of this and other services may be a widespread failure to appreciate that complex rehabilitation services which cross agency boundaries need members of these teams to have come from all relevant services. In addition, a senior clinician needs to work with a single senior manager. ${ }^{2}$

In summary, the rocks on which rehabilitation founders include shortage of staff, poor structures, low levels of technical investment and lack of audit and research.

\section{Technology}

External to the NHS, but potentially having a great bearing on demands for NHS support, much can (and needs to) be done. Smart housing and better communication systems with disabled people living at home have the largely unexplored potential to reduce admissions and institutionalisation.

Within the NHS, other promising initiatives include improved prostheses, sophisticated external and internal controlling devices and possibly robotics.

Prosthetic advances have been major. We have intelligent joints, much improved cosmesis and attempts, such as Gow's pro-digits, ${ }^{28}$ to deal with the lack of sensation and feedback of upper limb prostheses. The modular Campbell Aird arm is on trial though admittedly only in two persons and investment in this area is low.

There have been significant advances in environmental controls, assistive and communication technology. Yet prescription is circumscribed and there is some evidence that many more, often older, people could benefit from relatively simple technology. Again, research is limited.

Swain and colleagues have produced two external stimulators of movement, in paraplegia and hemiplegia; the former requires complex computerised programming; the latter is simpler. ${ }^{29,30}$ Stimulation of dorsiflexion of the foot is proven effective yet only a small proportion of hemiplegic subjects receive it. As its cost is of the same magnitude as a prescription of a new antibiotic, why is this? Perhaps it relates to the R\&D and prescription loop in the service. In commerce this is a simple circle with client demands and the market driving change (as with cars). In the NHS, the link between user or professional and the development of a better product seems more tenuous. The Audit Commission asserts that equipment services are locked in a vicious circle (Fig 2). ${ }^{31}$

Internally controlled devices have been well reviewed by Rushton. ${ }^{32}$ A wide range of neuroprostheses are available but their combination with drugs and physical therapy requires further exploration and more routine use of movement analysis and gait laboratories. Robotics seems to some like the land of the lotus-eaters - enticing and diverting. The incorporation of robotics into rehabilitation will be slow as there is little investment in this area. The little research being done does not yet translate into major practical advances.

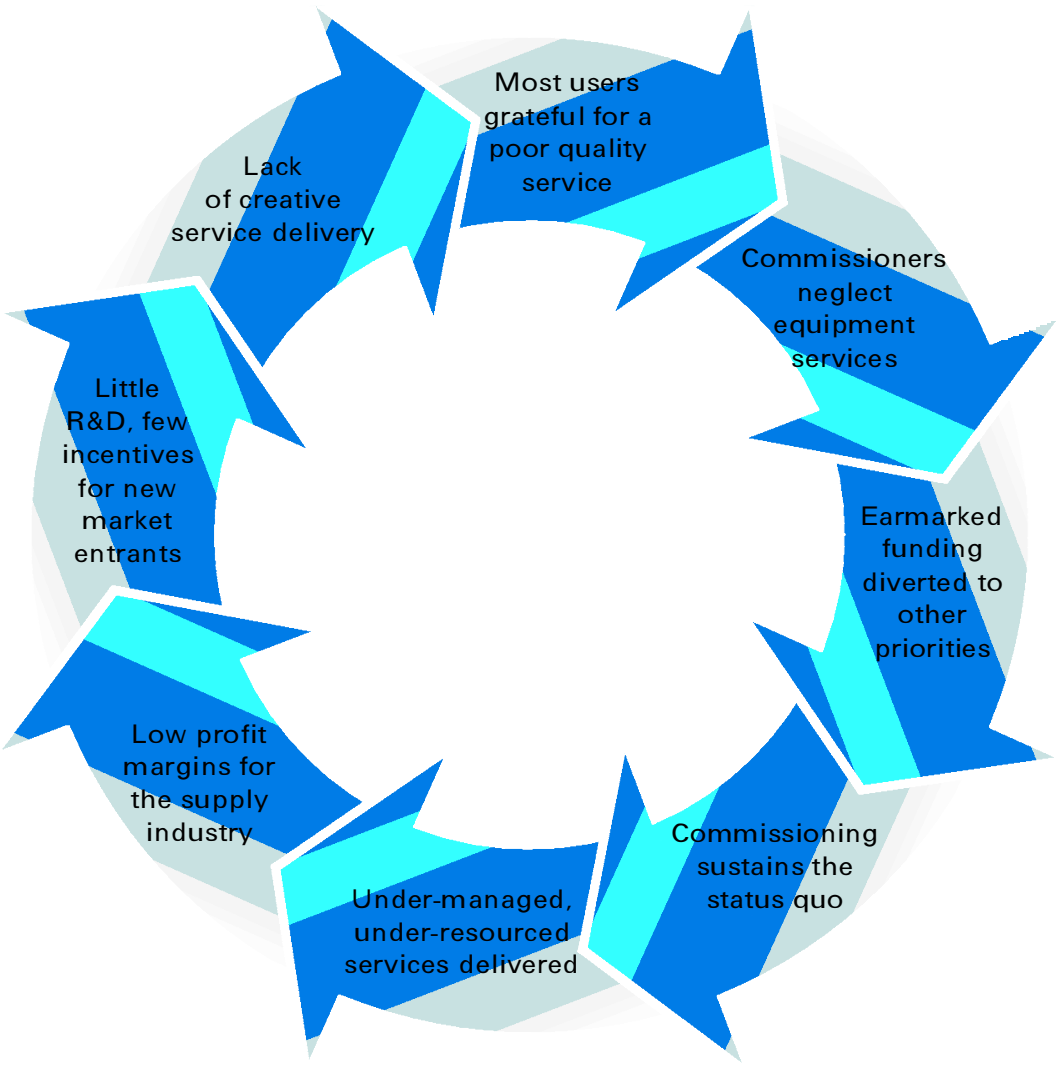

Fig 2. Equipment services locked in a vicious circle.

\section{Neuroplasticity and educational therapy}

Rehabilitation is largely a process of retraining or learning new things, often with a damaged nervous system. Neuroplasticity is generally recognised as important in a clinical context and important research work is being done, such as that of Wilson and her team on errorless learning. ${ }^{33}$ Yet Shallice, taking soundings from a neuropsychology conference in 2000, found delegates still felt that rehabilitation practice is not driven by theoretical understanding. ${ }^{34}$ Many feel that there should be greater application of current educational theory.

\section{Measurement}

This is probably one of rehabilitation's emerging strengths. Accurate, appropriate and sensitive measurement is central to clinical practice and research. ${ }^{35}$ Rehabilitation has made considerable advances from a low base and in a difficult area. Turner-Stokes ${ }^{36}$ produced for the BSRM a 'basket' of measures frequently used in the UK (www.bsrm.co.uk), and Tennant ${ }^{37}$ leads 
an EU collaborative group which is doing a similar study in 25 European centres. New measures have been produced and whilst it is easy to be diverted into producing increasing numbers of measures, we do need such things as sensitive measurement of returning cognition after severe brain injury. The Wessex Head Injury Matrix is promising. ${ }^{38}$

\section{Organisational studies}

These may seem duller but they are of the greatest importance. Few drug studies show an effect of the size of the improvement of mortality and morbidity which results when care is organised in stroke units. ${ }^{39}$ These studies are usually quoted in arguments for better stroke services, but they are probably a generic argument for the power of organisation. Our recent study of dedicated young adult services versus ad hoc services in four cities showed that the organised services cost no more than the disorganised ones but enabled some three times as many young people to participate in society. ${ }^{40,41}$ However, the organisation of rehabilitation has to be such that services are equitable for those with rare disorders: in the much needed development of stroke services, those with non-stroke neurological disability must not be left without provision.

\section{Conclusion}

Major advances have occurred in many areas - in prosthetics, in control devices of many sorts, in measurement and in organisation of services. But advances are not uniform in the many rehabilitation fields associated with chronic disease. Until research and clinical investment are commensurate with need, the disparity between potential outcome and reality will remain great. Many people in the UK do not get access to many of the advances outlined above. The continued development of academic rehabilitation research made in the last decade is threatened by lack of coherent funding. Too few clinical researchers work with senior scientists on permanent contracts and too much reliance is placed on those with short contracts to maximise the skills and data held in these departments: critical mass needs to be enhanced. Those with chronic conditions, a major part of the NHS's business, must be provided with a rapidly enlarging evidence base to drive increasingly effective practice.

\section{The way through}

Good rehabilitation practice can address many of the emerging demographic demands outlined above. It can address current needs: Age Concern have stated that rehabilitation is 'the missing link, the solution to the hospital bed crisis, and to the waiting list dilemma. ${ }^{42}$ As important, it can shrink and ameliorate the years of disability we must all expect. Faith in this ability and investment in those who undertake research in this area are the sine qua non of enabling our odyssey to succeed.

\section{References}

1 Homer. The Odyssey, The Iliad. London: Penguin Books,.

2 Marks L, McLellan DL, Langton-Hewer R, Ward C. Medical rehabilitation for people with physical and complex disabilities. A report from the Royal College of Physicians Committee on Rehabilitation Medicine. London: Royal College of Physicians, 2000.

3 Wade D. Research into rehabilitation. What is the priority? Clin Rehab 2001;15(3):229-32.

4 World Health Organization. Health systems: improving performance. The World Health Report 2000. Geneva: WHO, 2000.

5 Callahan D. Death and the research imperative New Engl J Med 2000;342(9):654-6.

6 Martin J, Meltzer H, Elliot D. The prevalence of disability among adults. OPCS surveys of disability in Great Britain, Report 1. Birmingham: OPCS, 1988.

7 Halstead LS, Grimby G. Post-polio syndrome. St Louis: Hanley \& Belfus (Mosby), 1994.

8 Hutton JL, Colver AF, Mackie PC. Effect of severity of disabilty on survival in north east England cerebral palsy cohort. Arch Dis Child 2000;83:468-74.

9 Stevenson CJ, Pharoah POD, Stevenson R. Cerebral palsy: the transition from youth to adulthood. Develop Med Child Neurol 1997;39:336-42.

10 David TJ. Transition from the paediatric clinic to the adult service. $J R$ Soc Med 2001;94(8):373-4.

11 Doyle, LW, Casalaz, D. Outcome at 14 years of extremely low birthweight infants: a regional study. Arch Dis Child Fetal Neonatal Ed 2001;85:F159-64.

12 Royal College of Surgeons of England and the British Orthopaedic Association. A Joint report. Better care for the severely injured. London: RCS and BOA, 2000.

13 Child health needs are ignored. The Independent: July 2000, p 10.

14 Sturms, LM, van der Sluis, CK, Groothoff, JW, ten Duis, HJ, Eisma, WH. Characteristics of injured children attending the emergency department: patients potentially in need of rehabilitation. Clin Rehab 2002;16:46-54.

15 Mattingly S. Rehabilitation today in Great Britain. Kingston: Kluwer Academic, 1977, 2nd edition 1981.

16 British Society of Rehabilitation Medicine. Vocational rehabilitation: the way forward. A working party report. London: BSRM, 2000.

17 Trade Union Congress. Creating a healthier nation - getting Britain back to work. Report of three TUC conferences on rehabilitation and job retention. London: TUC, 2000.

18 Pattani S, Costantinovici N, Williams S. Who retires early from the NHS because of ill health and what does it mean? BMJ 2001;7280:208-10.

19 Lerner DJ, Amick III BC, Malspeis S, Rogers WH. A national survey of health-related work limitations among employed persons in the United States. Dis Rehab 2000;22(5):225-32.

20 Warren M. The evolution of a geriatric unit from a Public Assistance Institution, 1935-1947. Proc R Soc Med 1948;41:337-8.

21 Mulley GP. In rehabilitation. Age Ageing 1994:23:S28-30.

22 Ebrahim S. Community care: implications for health services for elderly people. New agendas and challenges from the UK and overseas. In Challis D, Davies B, Traske K (eds), Community care. Aldershot: Arena, 1994.

23 Young J, Turnock S. Community care waiting lists and older people. BMJ 2001;322(7281):254.

24 Sinclair A, Dickinson E. Effective practice in rehabilitation: the evidence of systematic reviews. London: King's Fund, 1998.

25 Turner-Stokes L. The effectiveness of rehabilitation: a critical review of the evidence. Clin Rehab 1999;13(1)(Suppl).

26 McColl I. Review of the artificial limb and appliance centre services, Department of Health and Social Security. London: HMSO, 1986.

27 Bowker P. Fully equipped: the provision of equipment to older or disabled people by the NHS and social services in England and Wales, 2000. London: The Audit Commission, 2000. 
28 Gow DJ, Douglas W, Geggie C, Monteith E, Stewart D. The development of the Edinburgh modular arm system. Proc Inst Mech Eng [H] 2001;215(3):291-8.

29 Mann GE, Burridge JH, Ewins DJ, Swain ID et al. Optimising two channel stimulation to improve walking following stroke. Proceedings of the 5th Annual Conference of the International Functional Electrical Stimulation Society. California: IFESS, 2000:452-5.

30 Burridge JH, Taylor PN, Hagan SA, Wood DE, Swain ID. The effects of common peroneal stimulation on the effort and speed of walking: a randomised controlled trial with chronic hemiplegic patients. Clin Rehabil 1997;11;201-10.

31 Audit Commission. Fully equipped - assisting independence. London: Audit Commission, 2002.

32 Rushton D. Neuroprostheses, neuromodulators and rehabilitation. A report of the British Society of Rehabilitation Medicine. London: BSRM, 1997. Website: www.bsrm.co.uk

33 Evans JJ, Wilson BA, Schuri U, Audrade J et al. A comparison of 'errorless' and 'trial-and-error' learning methods for teaching individuals with acquired memory deficits. Neuropsychol Rehab 2000;10(1):67-101.

34 Shallice T. Cognitive neuropsychology and rehabilitation: Is pessimism justified? Neuropsychol Rehab 2000;10(3):209-17.

35 Sinclair A, Dickinson E. Effective practice in rehabilitation: the evidence of systematic reviews. London: King's Fund, 1998:9.

36 Turner-Stokes L. The effectiveness of rehabilitation: a critical review of the evidence. Clin Rehab 1999;13(1)(Suppl).

37 Tennant A, Grimby G, Marincek C, Phillips H et al. Standardising outcome measurement in physical medicine and rehabilitation across Europe. Euro Rehab 1999;3:178-80.

38 Shiel A, Wilson B, McLellan L, Horn S, Watson M. Wessex Head Injury Matrix. Reading: Thames Valley Test Co. Ltd, 2000.

39 Kalra L. The influence of stroke unit rehabilitation on functional recovery from stroke. Stroke 1994;25(4):821-5.

40 Bent N, Jones A, Mollow I, Chamberlain MA, Tennant A. Factors determining participation in young adults with a physical disability: a pilot study. Clin Rehab 2002;16(1):115.

41 Bent N, Tennant A, Swift T, Posnett J et al. Ad hoc or focussed services for young people with physical disabilities? The Lancet 2002 (in press).

42 Age Concern England. Ready to go home: rehabilitation re-discovered. London: Age Concern England, 1999. 